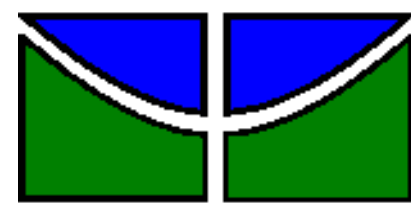

UNIVERSIDADE DE BRASÍLIA

Faculdade de Educação - UAB/UnB/ MEC/SECAD

Curso de Especialização em Educação na Diversidade e

Cidadania, com Ênfase na EJA

GEDAIS HOLANDA DE AGUIAR

JOSEANE MARIA DA ROCHA HOLANDA

\title{
RESGATE DA 3a IDADE À EJA
}

BRASÍLIA, DF

Julho/ 2010 
UNIVERSIDADE DE BRASÍLIA

Faculdade de Educação - UAB/UnB/ MEC/SECAD

Curso de Especialização em Educação na Diversidade e Cidadania, com Ênfase na EJA

\section{RESGATE DA 3a IDADE À EJA}

GEDAIS HOLANDA DE AGUIAR

JOSEANE MARIA DA ROCHA HOLANDA

PROFESSOR ORIENTADOR: Carlos Alberto Lopes de Sousa

TUTOR ORIENTADOR: Elvira Rodrigues Ribeiro

PROJETO DE INTERVENÇÃO LOCAL

BRASÍLIA, DF Julho/2010 
UNIVERSIDADE DE BRASÍLIA

Faculdade de Educação - UAB/UnB/ MEC/SECAD

Curso de Especialização em Educação na Diversidade e

Cidadania, com Ênfase na EJA

GEDAIS HOLANDA DE AGUIAR

JOSEANE MARIA DA ROCHA HOLANDA

\section{RESGATE DA 3a IDADE À EJA}

Trabalho de conclusão do Curso de Especialização em Educação na Diversidade e Cidadania, com Ênfase na EJA, como parte dos requisitos necessários para obtenção do grau de Especialista na Educação de Jovens e Adultos.

Carlos Alberto Lopes de Sousa

Professor Orientador

Elvira Rodrigues Ribeiro

Tutor Orientador

Carlos Angelo de Meneses Sousa

Avaliador Externo

BRASÍLIA, DF Julho/2010 
"Toda conquista merece um aplauso, e todo trabalho que Ihe tira gotas de suor merece mais que um aplauso, merece uma festa, pois todos que um dia conquistaram algo na vida deixaram algo de si pelo caminho da conquista. Por isso dedicamos o suor do nosso trabalho primeiramente a Deus e depois a todos que amamos". 
"O homem erudito é um descobridor de fatos que já existem - mas o homem sábio é um criador de valores que não existem e que ele faz existir".

Albert Einstein 


\section{RESUMO}

O projeto "Resgate da $3^{\text {a }}$ Idade à EJA" tem como principais objetivos o resgate e o incentivo aos idosos para retomarem os estudos a partir de uma participação efetiva do professor junto ao educando para proporcionar aos mesmos subsídios que garantam esse regresso e permanência, uma vez que são muitas as dificuldades impostas pela vida e até mesmo pelos próprios idosos no que se refere aos estudos. Os empecilhos relatados por vários dos estudantes são: cansaço após um dia árduo de trabalho, cuidar dos afazeres domésticos, e muito mais. As desculpas são inúmeras. Embora os estudantes idosos apresentem muitas dificuldades para se organizarem, muitos deles vêem o estudo como uma oportunidade única de serem pessoas ainda melhores e até mesmo de darem exemplo aos filhos e netos a aproveitarem o momento e o tempo que tem para estudar e ter um futuro melhor e mais digno. Pelo fato desses idosos não terem um estudo adequado, muitos dos seus filhos também não o tem e os filhos dos filhos e assim por diante. O projeto busca ajudar a essas pessoas a reconhecerem que necessitam a cada dia de uma melhor formação educacional, pois alguns estão também procurando melhorar os seus conhecimentos pelo simples fato de anotar um recado ao telefone ou até mesmo saber pegar um ônibus sem ter de perguntar para alguém.

Palavras-Chave: resgate, incentivo, dificuldades, idosos. 


\section{SUMÁRIO}

Introdução

1. Dados de Identificação do(s) Proponente(s)

1.1 Nome

1.2 Turma

1.3 Informações para contato

2. Dados de Identificação do Projeto

.09
2.1 Título
2.2 Área de abrangência
2.3 Instituição
2.4 Público ao qual se destina
2.5 Período de execução

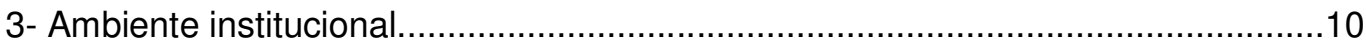

4- Justificativa e caracterização do problema.........................................................10

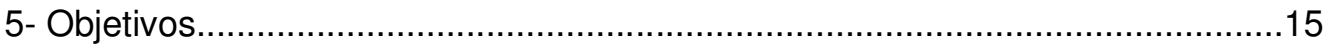

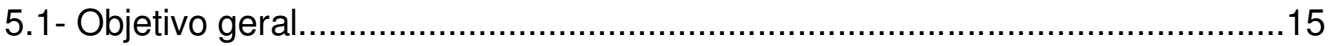

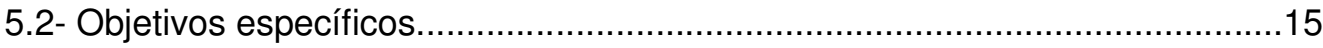

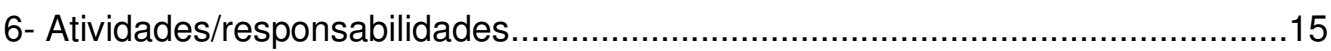

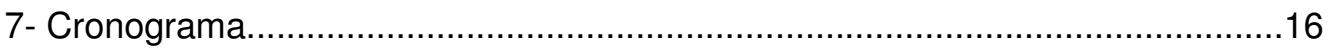

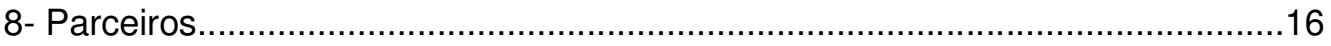

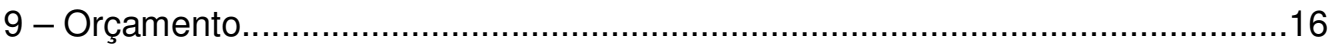

10- Acompanhamento e avaliação..............................................................16

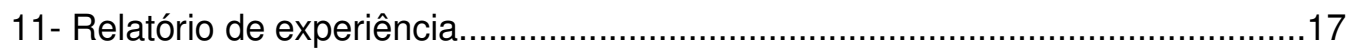

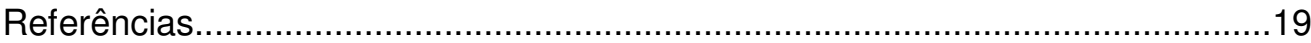

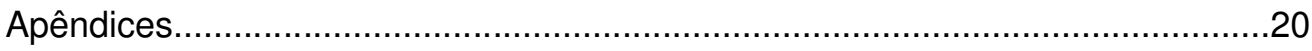




\section{INTRODUÇÃO}

O sistema de ensino brasileiro ao longo de sua história tem passado por um processo de transição, buscando novas alternativas pedagógicas que passam erradicar o analfabetismo no país, com programas que sirvam de incentivo a todos os jovens e adultos a buscarem o saber formal, mas mesmo assim os resultados não têm sido satisfatórios pelos órgãos competentes. A evasão escolar ao longo da implantação dos programas tem apresentado resultados negativos, tornando-se desafiador para o professor, manter a permanência do aluno na escola.

Não se trata de alfabetizar um mundo no qual a leitura era privilégio de poucos letrados, mas sim, para a formação humana, mediante os contextos sócio-culturais e históricos. Nesta visão de escola renovada o ensino para jovens e adultos merece uma atenção específica, a partir da seleção de seus currículos formulados dentro da contextualização coletiva, podendo abrir espaços e novas perspectivas de saberes integrando os conhecimentos científicos. O público da EJA merece considerações cuidadosas. A ela se dirigem jovens e adultos com suas múltiplas experiências de trabalho, de vida e de situação social.

Desse modo o Projeto Resgate da 3ํㅡㄹ Idade à EJA visa sobre tudo uma intensa participação e colaboração mútua no sentido de viabilizar o regresso dos idosos que por muitas razões desistem da caminhada, em nosso caso mais específico da alfabetização. Sendo assim esse projeto está organizado em tópicos nos quais são apresentados os roteiros de atividades desenvolvidas no mesmo, para que o projeto ganhe mais consistência estamos nos valendo de alguns autores como: Paulo Freire, Mário Sérgio Corttela, Tânia Maria de Melo Moura entre outros.

O projeto também conta com tabelas e um gráfico ilustrativo para a elucidação de como o projeto propiciou um regresso considerável de alunos as classes, e por fim apresentase um relatório detalhado dos acontecimentos, bem como os resultados obtidos com o projeto. 
1- Dados de identificação do(s) proponente(s):

1.1 Nome(s): Gedais Holanda de Aguiar e Joseane Maria da Rocha Holanda

1.2 Turma: "D"

1.3 Informações para contato:

Telefone(s): (61) 9138-4564 e (61) 9251-8666 E-mail: professorgedais@gmail.com e joseane12rocha@yahoo.com.br

2. Dados de identificação do Projeto:

2.1 Título: O Resgate da 3a idade à EJA

2.2 Área de abrangência: 1ำ segmento da EJA (Alfabetização)

Local

2.3- Instituição:

SESI - Serviço Social da Indústria localizado Avenida Araguaia, n⒈544, Edifício Albano Franco, Setor Leste Vila Nova, CEP 74.655.070, Goiânia - GO. Executado na comunidade Jardim Califórnia e Jardim América no Município de Águas Lindas de Goiás.

Nome: SESI - Serviço Social da Indústria em parceria com o Governo Federal

Endereço: Quadra 02 lote 16 Jardim Califórnia

Instância institucional de decisão:

SESI de Anápolis junto ao Governo Federal

\section{4- Público ao qual se destina:}

O projeto de intervenção local foi aplicado nas turmas de EJA primeiro segmento através da parceria do Governo Federal e o SESI de Anápolis o qual possui vários pólos no Município de Águas Lindas de Goiás. A nossa comunidade residente nos bairros Jardim Califórnia e Jardim América I cursam a alfabetização desde 2009 em uma casa cedida por uma igreja local, nesta casa cumprimos a difícil tarefa de colocar o nosso projeto em prática.

\section{5- Período de execução:}

Foi realizado no primeiro trimestre de 2010.

Início (mês/ano) Janeiro / 2010 Término: Abril / 2010 


\section{Ambiente institucional:}

O SESI pioneiro à época dos movimentos voltados ao desenvolvimento do incipiente processo de industrialização, o SESI dava seus primeiros passos em Goiânia, no início da década de 50, ao lado do SENAI, em Anápolis, e da Federação das Indústrias do Estado de Goiás (Fieg), que nasceram um pouco antes. Educação para o lar, assistência médica, odontológica, recreação e esportes constituíam as primeiras ações, pilares do amplo leque de serviços hoje oferecidos aos trabalhadores, seus dependentes e à comunidade, destinados a promover o desenvolvimento socioeconômico.

Instituição do Sistema Federação das Indústrias do Estado de Goiás (Fieg), o SESI consolidou-se como marca da responsabilidade social, ao promover de forma integrada educação, saúde e segurança no trabalho, lazer e cidadania, com qualidade reconhecida pela comunidade.

Presente com centros de atividades e colônia de férias em Goiânia, Anápolis, Aruanã, Aparecida de Goiânia, Catalão, Itumbiara e Rio Verde (pólo de atendimento na Escola SENAI Fernando Bezerra), a instituição amplia o atendimento por meio de unidades móveis de lazer, cultura, odontologia, saúde e segurança do trabalho, instalados temporariamente em indústrias, associações, escolas e espaços públicos. A mais recente experiência é o Cozinha Brasil, unidade itinerante por meio da qual o SESI proporciona educação alimentar a camadas mais carentes da população.

Fiel à missão institucional, o SESI tem atuação ágil e dinâmica em todo o Estado, com foco na melhoria da qualidade de vida do trabalhador e no fortalecimento da indústria.

Promover a qualidade de vida do trabalhador e de seus dependentes, com foco em educação, saúde e lazer, e estimular a gestão socialmente responsável da empresa industrial. Ser o líder nacional na promoção da melhoria da qualidade $d^{1} e$ vida do trabalhador e de seus dependentes. O histórico acima citado foi retirado da página oficial do SESI de Goiás. ${ }^{1}$

\section{4- Justificativa e caracterização do problema:}

Evasão: o conceito dessa palavra faz-se necessário para o melhor entendimento do que nos propusemos a fazer. De acordo com o Dicionário HOUAISS (2004), "EVASÃO significa: fuga, escapada; argumentação cheia de subterfúgios; pretexto." Então compreendemos essa palavra em nosso projeto como pretexto visto que os idosos tentaram

\footnotetext{
${ }^{1}$ http://www.sesigo.org.br/site/conteudo.php?id=10. Acesso em: 20/05/2010.
} 
usar muitos para não freqüentarem as aulas. Segundo a visão de Arroyo (1997, p.23), "na maioria das causas da evasão escolar a escola tem a responsabilidade de atribuir à

desestruturação familiar, e o professor e o aluno não têm responsabilidade para aprender, tornando-se um jogo de empurra". É justamente nesse ponto que nosso projeto é um diferencial, haja vista que ele nos propõe a aproximação do professor com a família diminuindo a distância que o sistema educacional coloca entre os dois.

Ao trabalhar com o $1^{\circ}$ segmento da EJA pudemos observar que a maioria dos alunos $e$ em nosso caso específico trabalhar com a alfabetização, percebemos que os alunos trabalham o dia inteiro fora do município de Águas Lindas, ou seja, no Distrito Federal retornam para casa quase que exclusivamente para dormir. E esse fato atrapalhou a participação dos mesmos nas aulas.

E para reverter esse quadro trabalhamos a questão da motivação para os idosos e a família que muitas vezes não colabora muito com o nosso trabalho. A motivação é um conceito central para a compreensão do comportamento humano, de acordo com Maria Aparecida Cória-Sabini (2000, p.83), "motivação é a força propulsora da conduta. É a condição interna que ativa o indivíduo e o predispõe a emitir certas respostas." Nesse sentido, fez-se necessário que cumpríssemos uma árdua tarefa a qual começou com a nossa visitação de casa em casa em nosso bairro para saber quem por ventura não era alfabetizado e tinha o interesse de participar de um projeto do SESI de Anápolis em parceria com o Governo Federal que traria a todos uma nova visão do mundo como diz Paulo Freire. E o máximo que conseguimos foram 30 alunos, a maioria de senhoras de idade, que lutam bastante pra sobreviver em nossa comunidade.

Visto a grande dificuldade enfrentada por nós professores de EJA e também pelos poucos recursos disponíveis a nós como educadores esse projeto se propôs a gerar possíveis soluções práticas para a evasão da $3^{\underline{a}}$ idade na EJA, tendo em vista alguns problemas locais e peculiares a temática elucidada no projeto.

O objeto deste projeto é lutar pelo regresso e permanência dos alunos da terceira idade na EJA do primeiro segmento. Pois, entendemos que de acordo com os artigos 205 e 214 da Constituição Federal de 1988:

Art. 205. A educação, direito de todos e dever do Estado e da família, será promovida e incentivada com a colaboração da sociedade, visando ao pleno desenvolvimento da pessoa, seu preparo para o exercício da cidadania e sua qualificação para o trabalho.

Art. 214. A lei estabelecerá o plano nacional de educação de duração plurianual, visando à articulação e ao desenvolvimento do ensino em seus diversos níveis e à integração das ações do poder público que conduzem à: 
I - erradicação do analfabetismo.

A educação não pode ser diferenciada no que diz respeito à lei, porquanto como a própria lei ressalta estamos incentivando e colaborando para o desenvolvimento da pessoa humana através da educação, tendo em vista, que a mesma na sociedade pós-moderna precisa de uma boa qualificação para o pleno exercício da cidadania. E como observadores e executores dessas leis supracitadas temos o maior prazer em praticar essa lei que promove a erradicação do analfabetismo pelas nossas mãos e que por outro lado ainda se arrasta em muitos estados da Federação por conta do descaso dos governantes que não dão os incentivos necessários aos educadores e educandos como a lei prevê.

O público da EJA merece considerações cuidadosas. A ela se dirigem jovens e adultos com suas múltiplas experiências de trabalho, de vida e de situação social. Há de se considerar também que o público da EJA está intimamente ligado ao trabalho, porque uma das grandes razões da evasão de acordo com Cória-Sabini é justamente o trabalho do aluno que por muitas vezes refém do emprego tem a árdua tarefa de em determinado momento escolher entre a escola e o trabalho.

Por outro lado no que tange a alfabetização desse trabalhador Paulo Freire (1996), nos elucida que, para que haja a alfabetização do adulto, não só é necessário o domínio dos códigos lingüísticos de codificar e decodificar. Mas, é prepará-los para o mundo através dos questionamentos, diálogos e o desenvolvimento crítico de suas ideias, orientando-os para viverem e conviverem com o mundo letrado e saber decifrar os códigos visuais da comunicação expostas pelos diversos segmentos sociais, do mundo letrado na qual o homem atual está em constante evolução.

Ainda segundo Paulo Freire há um princípio essencial: a alfabetização para jovens e adultos têm que partir da conscientização, jamais se pode separar da realidade ou dos fatos vividos pelos alunos. Hoje a alfabetização para jovens e adultos tem uma concepção libertadora, em que se questiona o debate dos saberes e tem toda liberdade de expressão, preocupando-se com a total integração dos indivíduos na sociedade. E tudo isso com certeza orienta nosso projeto no que tange a luta pela permanência do idoso na escola.

A seguir apresentamos uma tabela que nos apresenta a evasão antes de executarmos o projeto. 


\begin{tabular}{|c|c|c|}
\hline Alunos & Turma 1 & Turma 2 \\
\hline Jovens até 20 anos & 03 & 02 \\
\hline Adultos de 30 a 40 anos & 04 & 06 \\
\hline Idosos & 08 & 07 \\
\hline Total & 15 & 15 \\
\hline
\end{tabular}

Tabela 01 - Terceiro Trimestre 2009

Como todo início de projeto há uma grande expectativa por parte dos alunos. No primeiro momento divulgamos o projeto de erradicação do analfabetismo o qual é uma parceria do Governo Federal com o SESI de Anápolis, através de cartazes informativos os quais convidavam as pessoas que não puderam se alfabetizar na idade adequada, que os mesmos poderiam nos procurar na igreja local onde funcionava o pólo de alfabetização. E mesmo assim não conseguimos o mínimo de 15 alunos para iniciarmos o projeto, no entanto nós arregaçamos as mangas e fomos de porta em porta convidá-los, e como resultado, conseguimos 30 alunos, os quais foram separados em 02 (duas) turmas conforme a tabela acima. Nessa mesma tabela percebemos que o número de idosos é superior aos demais, o que mostra que a população com mais idade foram em um determinado tempo de suas vidas exclusas da escola.

Percebemos também que no terceiro trimestre de 2009 os alunos estavam bastante animados com o projeto, porém como toda escola existe aqueles que não conseguem se adaptar a mesma tão facilmente. Então observamos que os alunos começaram a faltar muito às aulas que só ocorriam três vezes por semana. E no quarto trimestre de 2009 começamos a nos deparar com pouquíssimos alunos principalmente os idosos.

Vejamos então a segunda tabela com os dados da evasão ocorrida principalmente por esses idosos do terceiro para o quarto trimestre de 2009. 


\begin{tabular}{|c|c|c|}
\hline Alunos & Turma 1 & Turma 2 \\
\hline Jovens até 20 anos & 02 & 02 \\
\hline Adultos de 30 a 40 anos & 04 & 04 \\
\hline Idosos & 03 & 02 \\
\hline Total & 09 & 08 \\
\hline
\end{tabular}

Tabela 02 - Quarto Trimestre 2009

Observamos que no quarto trimestre de 2009 através da tabela 02, que houve um percentual de evasão de aproximadamente 37,5\% dos idosos da turma 01 e na turma 02 a evasão foi de $28,57 \%$, dessa forma ficamos muito preocupados com tamanha desistência. Contudo, resolvemos como uma das primeiras medidas irmos as residências desses idosos desistentes e percebemos que para a maioria deles, além da estrutura precária na qual ocorriam as aulas e o pouco tempo que alegavam ter pelo fato de trabalharem o dia todo no DF e chegar em casa e fazer as tarefas domésticas no casa das senhoras que eram a maioria, disseram para nós também que faltavam coisas simples como um cafezinho, um lanche, que serviria como um tipo de incentivo para o regresso dos mesmos as aulas. Mas com tudo isso "cortamos um dobrado" para recuperarmos esses alunos para as salas novamente e mesmo assim não conseguimos o regresso de todos.

Além do incentivo do lanche também elaborávamos as aulas com mais sensibilidade pedindo aos alunos que nos dessem sugestões de temas afins. Passamos a introduzir várias dinâmicas sócio-educativas, e também abordamos temas da alfabetização que remetesse as suas atividades profissionais.

Após verificarmos a evasão de idosos em maior porcentagem nas turmas de EJA e posteriormente quando aplicamos já no $1^{\circ}$ trimestre de 2010 o nosso projeto verificou como pode se observar no gráfico abaixo: 


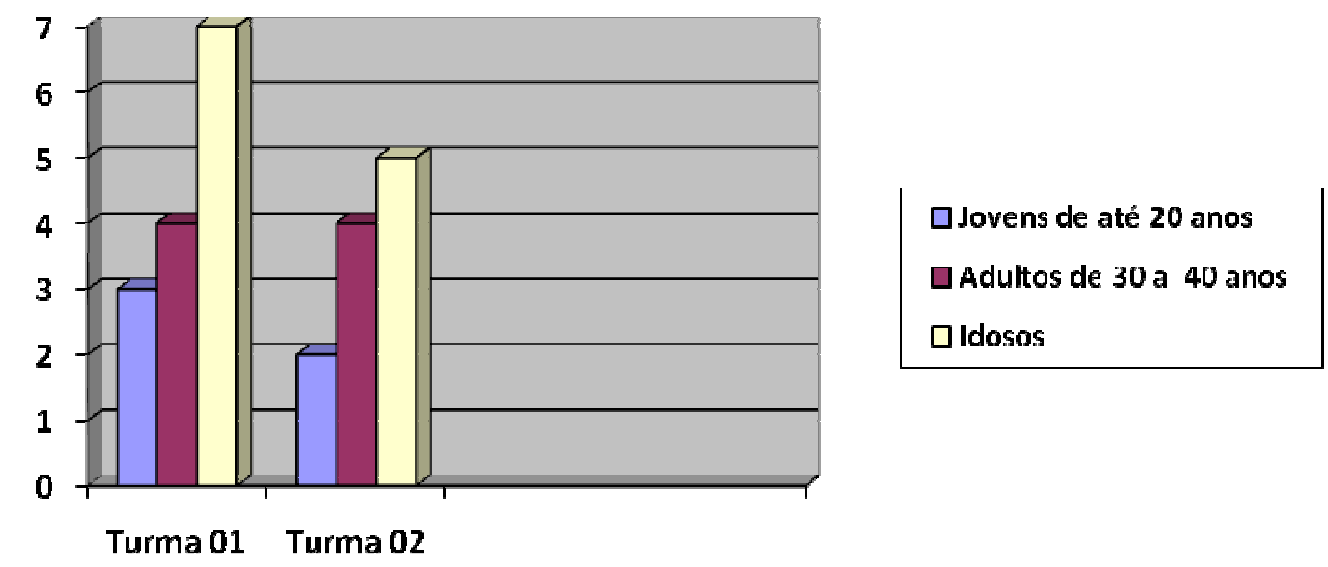

Gráfico 01- Aplicação do projeto no $1^{\circ}$ trimestre de 2010

O gráfico acima nos revela que nesse primeiro trimestre de 2010, na turma 01 obtivemos o regresso de 04 alunos idosos dos primeiros oito da tabela 01 e na turma 02 obtivemos o regresso de 03 alunos idosos dos primeiros sete da tabela 01 , portanto entendemos que quando transformamos o nosso ambiente de sala de aula num ambiente mais agradável e acolhedor conquistamos a confiança desses idosos, os quais entenderam em sua maioria os esforços por nós empregados para o benefício dos mesmos. Ou seja, como Paulo Freire cita em seus livros, nós respeitamos o mundo de saber desses alunos idosos e eles creditaram a nós a possibilidade de esclarecimento e iniciação às primeiras letras.

\section{Objetivos:}

\section{1- Objetivo Geral:}

Desenvolver estratégias para 0 regresso e a permanência dos alunos da $3^{a}$ idade na alfabetização.

\section{2- Objetivos específicos:}

Gerar possíveis soluções práticas para a evasão da $3^{\text {a }}$ idade na EJA, tendo em vista alguns problemas locais, resignificando o ambiente de aprendizado, de forma a promover a motivação para o regresso dos alunos às aulas.

\section{2- Atividades/responsabilidades:}


- Visitações semanais e programadas para acompanhamento dos educandos. Passamos a visitar aqueles alunos que tinham mais de duas faltas semanais e nessas visitações indagamos os mesmos os motivos de não estarem freqüentando as aulas. As repostas que

obtivemos foram as mais diversas como: falta de tempo; cansaço do trabalho; afazeres domésticos dentre outros. E nessas visitações os alunos foram aconselhados por nós professores a organizarem o seu dia de forma que eles pudessem ir à escola.

- Coordenação de dinâmicas coletivas feitas com a participação e organização dos alunos. Cada aluno trouxe uma fruta de casa e na hora da aula eles colocaram as frutas num cesto e as cobriram, cada um ia ao cesto e pagava uma fruta, a fruta que o aluno pegasse tinha que escrever o nome dela no quadro. Houve também o momento trabalhador em que os alunos traziam objetos ou instrumentos do seu próprio trabalho para descrever a utilidade dos mesmos a turma. $E$ tais utilidades eram trabalhadas no processo de alfabetização dos alunos.

- Escrever os nomes de pessoas da família em um cartaz e apresentar a turma, tais como ilho, neto, marido.

- Viabilização do momento trabalhador "conte-nos o seu dia". Em cada aula nos primeiros cinco minutos escolhíamos um aluno para contar como havia sido o seu dia. E através desses momentos passamos a entender melhor a situação dos nossos alunos como um todo. Desse modo conseguimos perceber o que precisaríamos fazer para que cada um pudesse ser mantido no projeto de alfabetização.

- Responsáveis: Gedais e Joseane

\section{Cronograma:}

Executamos o projeto praticamente nos meses de Janeiro, Fevereiro e Março de 2010. Sempre as terças, quintas e sábados. Com as visitações e os encontros promovidos na igreja de 4 horas aula.

\section{Parceiros:}

Tivemos a parceria e o apoio do SESI de Anápolis e do Governo Federal.

\section{Orçamento:}

Como a comunidade é pequena nós não tivemos gastos aparentes, uma vez que fizemos as visitações e compramos o lanche com dinheiro de nós mesmos professores, e algumas vezes as próprias alunas senhoras traziam algo de suas casas, ou seja, não tivemos custos.

\section{Acompanhamento e avaliação:}


A nossa avaliação não foi e nem poderia ser semelhante a algum padrão usual atual, tendo em vista que utilizamos como um dos principais fatores para que esse projeto funcionasse era justamente a visitação e a melhor acomodação desses alunos idosos,

portanto, a nossa avaliação se baseia no fato de que conseguimos um regresso significativo como as tabelas e gráfico desse projeto apresentam o regresso dos idosos às aulas.

\section{Relatório de experiência}

O primeiro passo para que esse projeto viesse a frente foi termos observado o número crescente de evasores de nossas classes e isso nos fez pensar como reverter esse quadro que era mais grave como os alunos (as) mais velhos. E para conseguirmos alcançá-los novamente e trazê-los para a sala de aula não foi nada fácil. Contudo, podemos dizer que obtivemos bons resultados, uma vez que conseguimos que boa parte dos alunos regressassem, por vias de muitas visitas programadas, muitos telefonemas, dinâmicas de grupo nos sábados e um bom lanchinho. Mas também tivemos que ter muita paciência ou porque não dizer a "Parcimônia Verbal" como dizia Paulo Freire para conseguirmos criar o desejo no coração de pessoas idosas a continuarem suas alfabetizações. Por isso deixamos claro que nosso maior objetivo além do regresso desses alunos era sem sobra de dúvidas a aproximação entre o professor e o aluno nesse processo tão especial de alfabetizar.

Em nosso percurso acreditamos ter apreendido bastantes informações que os colegas postaram via e-mail, com certeza nos ajudaram e acredito que também nós ajudamos com nossos textos aos colegas reciprocamente e acreditamos no potencial desse projeto de aproximação e motivação com fim tal de evitar a evasão pela intervenção direta do próprio professor.

Compreendemos também que vários tópicos trabalhados em nosso percurso influenciaram em nosso projeto, no início nossa maior dificuldade de aplicar e desenvolver o nosso projeto que é bastante prático e simples foi o "medo" de visitar essas pessoas e de repente ser mal interpretado ou não conseguir convencê-los pelos meios pedagógicos que conhecemos, mas no fim conseguimos bastante aceitação em nosso trabalho.

Em uma de nossas visitas uma senhora que era nossa aluna disse que não estava freqüentando as aulas simplesmente porque o seu netinho de 18 anos só ia para escola quando ela uma senhora de 65 anos esquentava o seu jantar, o que lhe atrapalhava, pois o garoto ia pra a escola por volta das 7:30 h e nossa aula começava as 7:00 h. Então nós entramos na questão familiar até interessante um jovem de 18 anos não poder esquentar o 
seu jantar e ficar esperando pela sua avó pareceu até hilário, mas nós demos um jeitinho de começar mais tarde as aulas, diminuído a carga de horas aulas semanais e aumentando a mesma nos sábados.

Como está exposto no corpo teórico desse projeto nós conseguimos bons resultados com esse projeto de incentivo e aproximação, pois os alunos que visitamos em sua maioria 07 (sete) idosos retornaram para as aulas, mesmo diante de algumas dificuldades enfrentadas por nós no decorrer dessas visitas. E também estão anexados a esse projeto, fotos que revelam um de nossos encontros no decorrer do projeto onde uma de nossas alunas de 72 anos havia feito um bolo para o lanche de suas colegas e revela um pouco da recuperação dos evasores do curso de alfabetização.

Após o projeto ser executado ficou evidente para o SESI que ações de resgate de alunos dentro da família como a que projeto evidenciou, enriquecem a instituição e aponta para possíveis soluções que visam o melhoramento da educação na forma de relacionamento da escola com a família, e com certeza o trabalho desenvolvido em forma de projeto vai ajudar a diminuir a evasão. E no que tange ao educando ficou um grande incentivo para que ele possa prosseguir os seus estudos com o intuito de uma melhor aceitação no mercado de trabalho, na sociedade e principalmente na família.

Por fim, o mais gratificante desse projeto é poder ouvir de uma senhora de idade que nunca pode ajudar seus filhos quando estudavam e que agora está pelo menos ajudando o netinho nas lições de casa. 


\section{REFERÊNCIAS}

ARROYO, Miguel G. da. Escola coerente à Escola possível. São Paulo: Loyola, 1997

(Coleção Educação popular - $n^{\circ}$ 8.)

CAGLIARI, Luiz Carlos. Alfabetização e lingüística. 6 ed. São Paulo: Scipione, 1995.

CONSTITUIÇÃO, Brasil 1988. Constituição da República Federativa do Brasil: Senado

Federal, Subsecretaria de Edições Técnicas, 2005. Art. 205 e Art. 214.

CORTELLA, Mário Sérgio. Evasão escolar: matrícula é uma coisa, freqüência, outra. In:

ABC educativa - São Paulo: Criarp Ltda.

FREIRE, Paulo. Educação como prática da liberdade. 26 ed. Rio de Janeiro-RJ: Paz e

Terra, 1994.

Pedagogia da autonomia. 13 ed. São Paulo: Paz e Terra, 1996.

MEC. Educação de Jovens e Adultos - Ensino Fundamental: proposta curricular - 1ํำ

segmento. São Paulo/Brasília. Ação Educativa/SEF, 1999.

MENEGOLLA, M. Didática: aprender a ensinar. 5 ed. São Paulo: Loyola, 1999.

MOURA, Tânia Maria de Melo. A prática pedagógica dos alfabetizadores de jovens e

adultos: contribuições de Freire, Ferreiro e Vygotsky. 2 ed. Maceió: EDUFAL, 2001.

AZEVEDO, Francisca Vera Martins. Causas e conseqüências da evasão escolar no ensino de jovens e adultos na escola municipal "Espedito Alves" - ANGICOS/RN. Disponível em:

http://webserver.falnatal.com.br/revista nova/a4 v2/artigo 13.pdf. Acesso em: 20 /05/2010

http://www.sesigo.org.br/site/conteudo.php?id=10. Acesso em: 20/05/2010 
APÊNDICES 


\section{Entrevista com a senhora Maria Leny Silva Bezerra de 60 anos uma de nossas alunas da $3^{\text {a }}$ idade resgatada da evasão pelo projeto.}

1. O que levou a senhora a desistir do curso de alfabetização?

R: Eu tinha muita dificuldade de sair da minha casa para ir ao colégio, é porque como eu cuido da minha casa e cuido do neto quando o neto chega do trabalho eu tenho que preparar a janta pra ele ir para o colégio estudar, então eu tive como ir para o colégio e me desanimei.

2. Depois que aplicamos o nosso projeto e passamos a the acompanhar mais de perto, isso mudou o quê na sua vida?

R: Eu tive prazer de ir para o colégio de pegar meu caderninho e estudar, porque eu tinha muita vontade de aprender a ler, mas como eu não tinha condição de ir com esse projeto eu me animei e voltei a estudar.

3. Qual a principal razão de a senhora ter regressado ao curso?

R: Eu achei mais facilidade com os professores mais perto, eu achei mais facilidade de voltar e ai os professores falaram com a gente eu tinha muita vontade de voltar a estudar e ai eu voltei pra estudar.

4. O que a senhora aprendeu com esse projeto, e cite para nós um momento inesquecível que vivenciou dentro dele?

R: Eu aprendi que é muito bom a gente voltar a estudar, porque eu sinto muita alegria quando eu consegui é.... ajuntar as letras ... é fazer o meu nome foi um prazer muito grande, porque agora eu posso ler, escrever meu nome quando precisar.

5. Houve alguma transformação familiar ou até mesmo social na sua vida?

R: Houve porque ai os meus netos me deram força também e se alegraram, porque eu já sei ler voltei a estudar com o incentivo dos professores. E eles gostaram também e eu também fiquei muito feliz, porque eu sei ler e escrever.

6. Em sua opinião o projeto conseguiu levantar a auto-estima dos idosos que estudam na EJA?

$R$ : É sim. E aconselho quem puder nos assistir que não perca a oportunidade de ajudar, porque é muito bom.

7. Em sua opinião, o professor com o aluno, houve uma aproximação com a sua família?

R: Houve como os professores são muito bons eles vem na casa da gente aconselha a gente, então é um incentivo que a gente antigamente não tinha e hoje em dia a gente tem de poder voltar a estudar, porque a família é faz parte da escola. E como os professores incentivando é muito bom. 
IMAGENS:

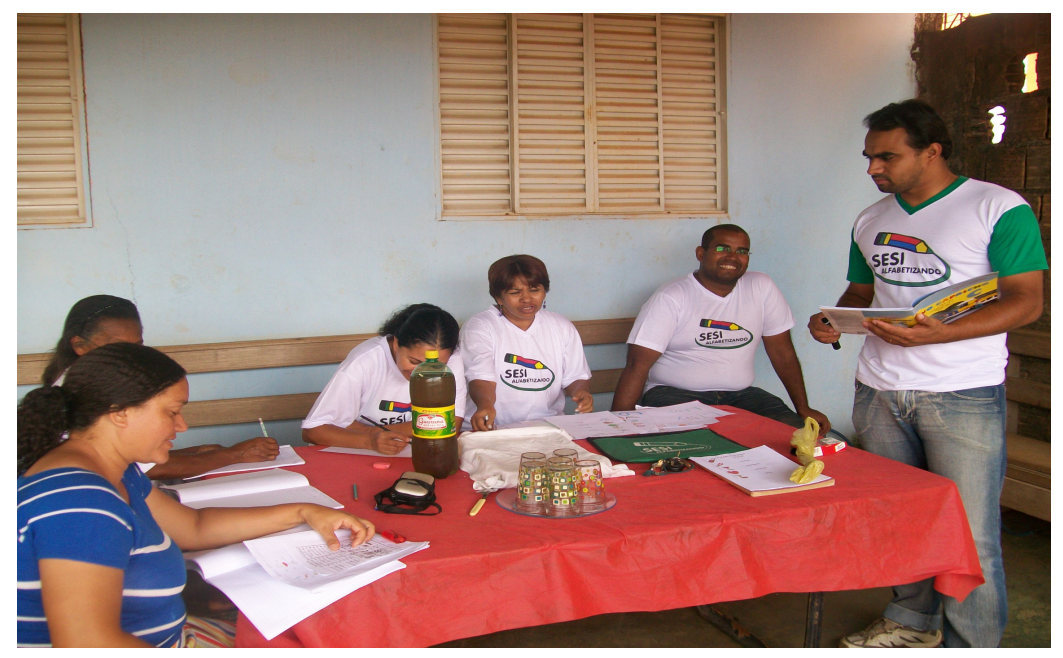

Figura 01: aula turma "A". Espaço cedido pela Igreja local Jardim Califórnia. Dezembro 2010

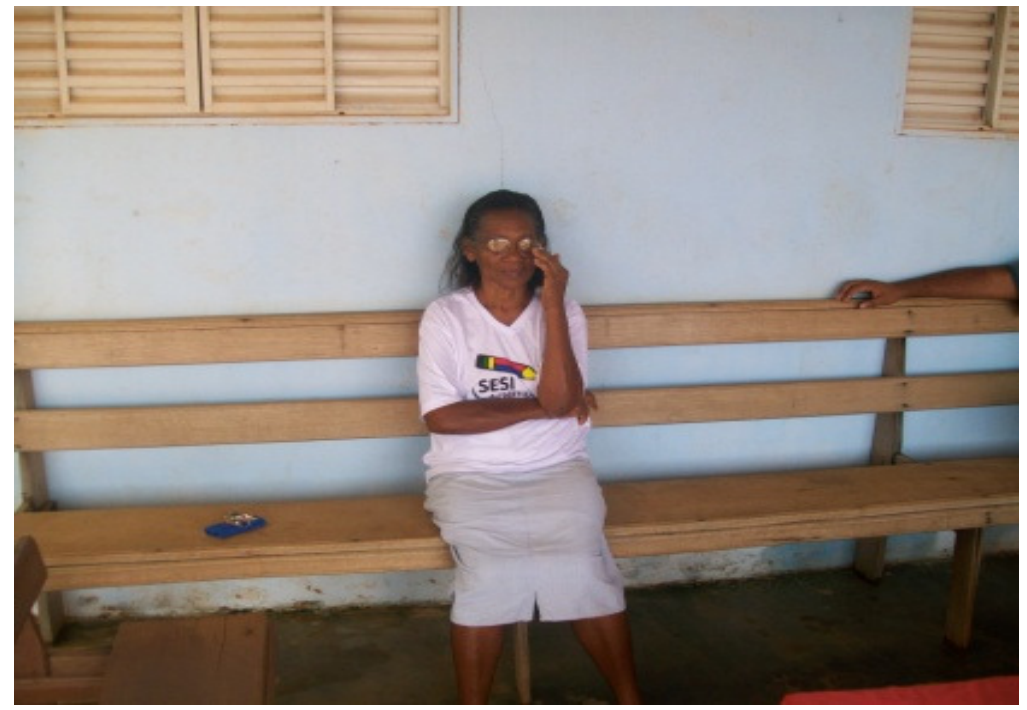

Figura 02: Senhora Luiza 70 anos. Espaço cedido pela Igreja local Jardim Califórnia. Dezembro 2009 